\title{
Fulminant hepatic and multiple organ failure following acute viral tonsillitis: a case report
}

\author{
Ursina Bechtel-Grosch', Charles Beguelin², Sabina Berezowska ${ }^{3}$, Jean-Francois Dufour ${ }^{4}$, Jukka Takala ${ }^{1}$ and \\ Joerg C. Schefold ${ }^{1 *}$
}

\begin{abstract}
Background: Pyogenic tonsillitis may often be observed in the general Western population. In severe cases, it may require antibiotic treatment or even hospitalization and often a prompt clinical response will be noted. Here we present an unusual case of progressive multiple organ failure including fulminant liver failure following acute tonsillitis initially mistaken for "classic" pyogenic (that is bacterial) tonsillitis.

Case presentation: A 68-year-old previously healthy white man was referred with suspicion of pyogenic angina. After tonsillectomy, he developed acute liver failure and consecutive multiple organ failure including acute hemodynamic, pulmonary and dialysis-dependent renal failure. Immunohistopathological analysis of his tonsils and liver as well as serum polymerase chain reaction analyses revealed herpes simplex virus- 2 to be the causative pathogen. Treatment included high-dose acyclovir and multiorgan supportive intensive care therapy. His final outcome was favorable.

Conclusions: Fulminant herpes simplex virus-2-induced multiple organ failure is rarely observed in the Western hemisphere and should be considered a potential diagnosis in patients with tonsillitis and multiple organ failure including acute liver failure. From a clinical perspective, it seems important to note that fulminant herpes simplex virus-2 infection may masquerade as "routine" bacterial severe sepsis/septic shock. This persevering condition should be diagnosed early and treated goal-oriented in order to gain control of this life-threatening condition.
\end{abstract}

Keywords: Critical illness, Hepatitis, MOF, Sepsis, Septic shock, Viral infection

\section{Background}

In the general Western population, pyogenic (that is bacterial) tonsillitis may often be observed and it is known to account for a large number of pre-clinical consultations. In severe cases, it may require antibiotic treatment or even hospitalization and a prompt clinical response will often be noted [1-3]. Here we present an unusual case of progressive multiple organ failure including fulminant liver failure following acute nonbacterial tonsillitis. We will furthermore report and discuss pitfalls in the clinical management of such life-threatening non-bacterial tonsillitis.

\footnotetext{
* Correspondence: joerg.schefold@insel.ch

${ }^{1}$ Department of Intensive Care Medicine, Inselspital, Bern University Hospital, $\mathrm{CH} 3010$ Bern, Switzerland

Full list of author information is available at the end of the article
}

\section{Case presentation}

A 68-year-old white man with an insignificant past medical history (including sexual history) was referred to our tertiary care academic center with symptoms of acute tonsillitis, clinically not responding to antibiotic treatment with oral amoxicillin-clavulanic acid. Following a 2-day course of moderate fever $\left(38{ }^{\circ} \mathrm{C}\right)$ and sore throat with highly elevated infection parameters of C-reactive protein $280 \mathrm{mg} / \mathrm{l}$, white blood cell count (WBC) $4.8 \mathrm{G} / \mathrm{L}$, and platelets $106 \mathrm{G} / \mathrm{L}$, he was hospitalized for intravenous antibiotic treatement. An initial physical examination at admission was unremarkable. Due to a progressive elevation in his inflammatory markers along with clinical deterioration and progressive tonsillar inflammation, a left-sided tonsillectomy was performed 48 hours after his hospital admission. 
During his postoperative course, fulminant acute liver failure (ALF) was observed and he was transferred to our intensive care unit (ICU) for further investigations and supportive intensive care treatment.

At ICU admission, laboratory analyses revealed leukopenia $(1.8 \mathrm{G} / \mathrm{l})$ with pan-lymphopenia and marked elevation of indices of liver dysfunction (Table 1). Toxic, vascular/ischemic, autoimmune, or metabolic liver disease was considered unlikely following anamnesis and respective laboratory tests (please also refer to Table 1). In addition to laboratory signs of ALF, the patient soon developed acute kidney injury/failure: risk, injury, failure, loss of kidney function, and end-stage kidney disease (RIFLE) category "F". An emergency abdominal ultrasound revealed moderate hepatic steatosis, and computed tomography imaging revealed inhomogeneous hepatic steatosis, ascites and moderate splenomegaly. A retropharyngeal abscess was ruled out. Infective tonsillitis-induced septic shock with progressive multiple organ failure was suspected and the initial antibiotic treatment using amoxicillin-clavulanic acid was changed to ciprofloxacin, Cubicin (daptomycin) and metronidazole. During the further course of the disease, supportive medical treatment included high-dose acetylcysteine, vitamin $\mathrm{K}$ and lactulose. However, further worsening of liver function tests was noted and a decision

Table 1 Paraclinical presentation at intensive care unit admission. Reference ranges are indicated

\begin{tabular}{llll}
\hline C-reactive protein & $<5$ & $\mathrm{mg} / \mathrm{L}$ & 393 \\
Creatinine & $59-104$ & $\mathrm{\mu mol} / \mathrm{L}$ & 158 \\
Aspartate aminotransferase & $<50$ & $\mathrm{U} / \mathrm{L}$ & 3829 \\
Alanine aminotransferase & $<50$ & $\mathrm{U} / \mathrm{L}$ & 2310 \\
Gamma-glutamyltransferase & $<60$ & $\mathrm{U} / \mathrm{L}$ & 148 \\
Ammonia & $15-55$ & $\mu \mathrm{mol} / \mathrm{L}$ & 94 \\
Bilirubin, total & $<17$ & $\mu \mathrm{mol} / \mathrm{L}$ & 101 \\
Bilirubin direct & $<5$ & $\mu \mathrm{mol} / \mathrm{L}$ & 97 \\
Glucose & $4.56-6.38$ & $\mathrm{mmol} / \mathrm{L}$ & 8.4 \\
Prothrombin time & $70-130$ & $\%$ & 64 \\
Factor V & $78-153$ & $\%$ & 45 \\
Hemoglobin & $135-168$ & $\mathrm{~g} / \mathrm{L}$ & 134 \\
Thrombocytes & $140-380$ & $\mathrm{G} / \mathrm{L}$ & 53 \\
Leukocytes & $3.5-10.5$ & $\mathrm{G} / \mathrm{L}$ & 1.8 \\
Neutrophils & $1.60-7.40$ & $\mathrm{G} / \mathrm{L}$ & 1.66 \\
Eosinophils & $0.02-0.40$ & $\mathrm{G} / \mathrm{L}$ & 0.01 \\
Basophils & $0.00-0.15$ & $\mathrm{G} / \mathrm{L}$ & 0 \\
Monocytes & $0.20-0.93$ & $\mathrm{G} / \mathrm{L}$ & 0.02 \\
Lymphocytes & $1.10-3.50$ & $\mathrm{G} / \mathrm{L}$ & 0.09 \\
Neutrophil bands & $3-18$ & $\%$ & 63.5 \\
Segmented neutrophils & $35-67$ & $\%$ & 29 \\
\hline
\end{tabular}

for a transjugular liver biopsy was established 48 hours following his ICU admission. Initial histologic findings revealed diffuse hepatic necrosis compatible with viral hepatitis (Fig. 1); empirical antiviral treatment using ganciclovir (500 mg single-shot, followed by $450 \mathrm{mg}$ twice a day) was commenced in order to cover cytomegalovirus (CMV) and herpes simplex virus (HSV). In addition, initial results showed seropositivity for HSV-2 immunoglobulin G (IgG), Epstein-Barr virus (EBV) IgG and CMV IgG. Serological testing for human immunodeficiency virus (HIV) and for hepatitis B and hepatitis $C$ revealed negative results. Final histological results of his liver then demonstrated significant HSV-1 and HSV-2 immunopositivity. In combination with strongly elevated HSV-2 serum polymerase chain reaction (PCR) levels $\left(10^{6}\right.$ to $10^{7} \mathrm{HSV}-2$ copies/ml) a formal diagnosis of HSV-2-positive hepatitis was established and treatment with ganciclovir was changed to acyclovir. The antibiotic therapy was stopped at this point in time. Due to strong HSV-positivity of hepatic tissue, tonsillar histologies were re-evaluated for HSV and marked respective immunopositivity was noted (Fig. 1). Thus, clinical and histological data strongly suggested primary HSV-2 tonsillitis.

Along with the development of fulminant ALF, the major clinical concern was progressive multiple organ failure. Despite initial "rescue"-steroid dosing, high doses of norepinephrine (peak dose of $0.3 \mu \mathrm{g} / \mathrm{kg} /$ minute) were required and progressive capillary leak was observed. Following a consecutive 48-hour trial of noninvasive ventilation, the patient required invasive mechanical ventilation as a consequence of progressive muscular exhaustion. He subsequently developed anuric acute renal failure and renal replacement therapy with intermittent hemodialysis was initiated. Due to deranged coagulation in which his platelet count was $56 \mathrm{G} / \mathrm{l}$, prothrombin time was $38 \%$, and international normalized ratio (INR) was 1.82 , with recurrent bleeding at the tonsillectomy site and progressive disseminated intravascular coagulation, an operative revision with ligation of tonsillar arteries was deemed necessary. High urgency liver transplantation was discussed as a therapeutic option but was refrained from due to persisting uncontrolled infection/multiple organ failure with an expected badverse outcome.

During his course at the ICU, repeated drainage of ascites was necessary. Aspartate aminotransferase (ASAT) and alanine aminotransferase (ALAT) serum levels peaked at day 3 (ASAT 6126U/l, ALAT 3377U/l), and elevated serum ammonia $(123 \mu \mathrm{mol} / \mathrm{l})$, alkaline phosphatase levels (520 U/l), and total bilirubin levels were noted (Fig. 2). His serum factor $\mathrm{V}$ levels were $24 \%$ at their lowest (following prior infusion of fresh frozen plasma). Continuous norepinephrine application was required for the ensuing 7 weeks due to severe vasoplegic shock and capillary leak. 

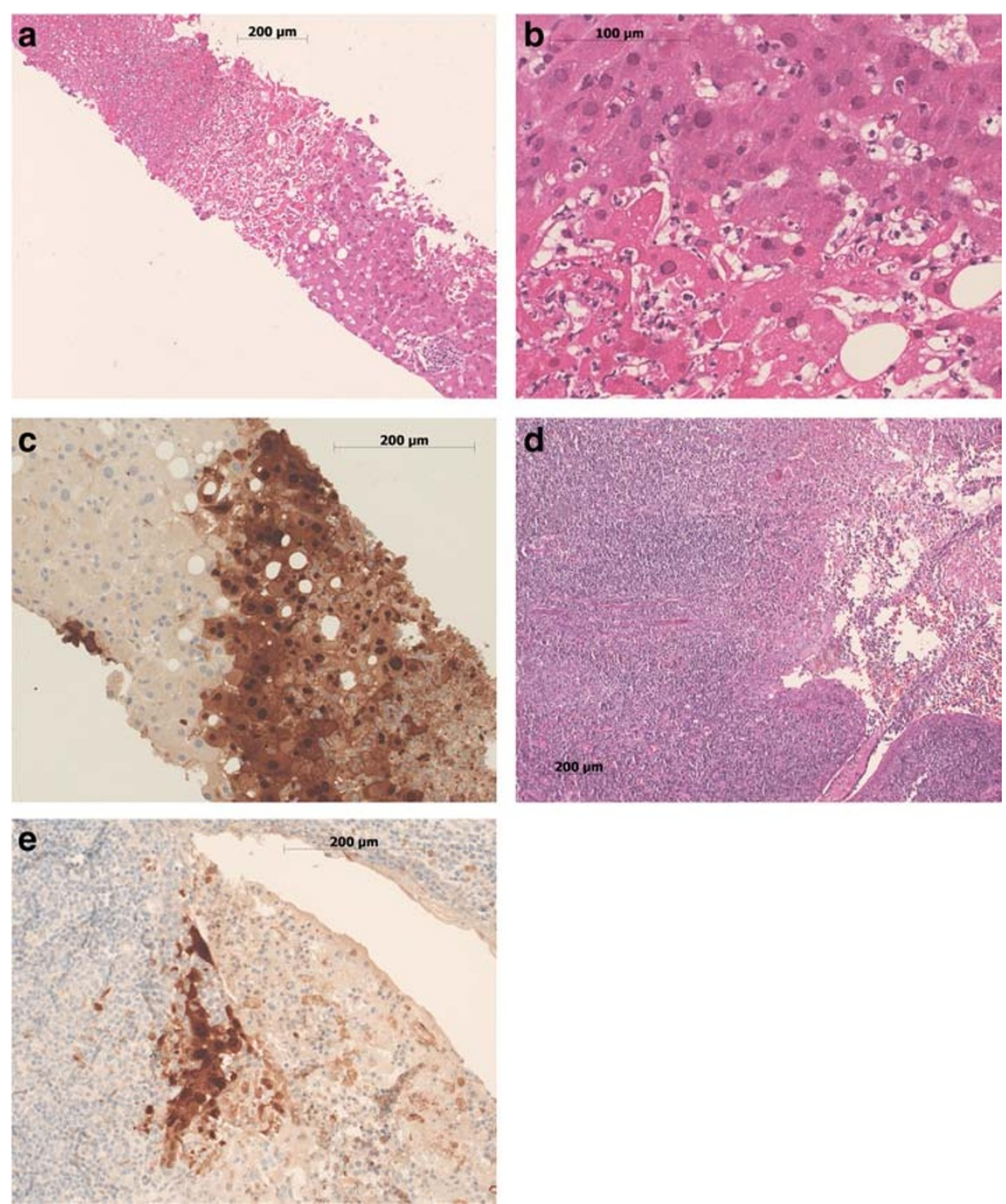

Fig. 1 Hepatic (a-c) and tonsillar (d-e) histology. Liver biopsy tissue shows patchy necrosis comprising 20 to $30 \%$ of the submitted tissue (a hematoxylin and eosin $\times 100$ ), with nuclear viral inclusions (b hematoxylin and eosin $\times 400$ ), immunohistochemically positive for herpes simplex virus-2 antigen $(\mathbf{c} \times 400)$. Tonsillar tissue examination discloses acute ulcerating tonsillitis (d hematoxylin and eosin $\times 100)$ with patchy positivity for herpes simplex virus-2 antigen in some remnants of surface epithelium adjacent to the ulcer and in necrotic tissue overlying the ulcer $(\mathbf{e} \times 200)$. Photomicrographs were taken on a Zeiss Axiophot2 microscope

Extensive sepsis-induced generalized edema was noted and cardiogenic failure was ruled out by repeated echocardiography. As weaning from mechanical ventilation was complicated by capillary leakage and consecutive volume overload, a dilative tracheostomy was performed at day 12. In the ensuing days, anuria persisted and continuous veno-venous hemodiafiltration was performed. Repeated cultures of urine, blood, sputum and stool specimens all revealed insignificant microbiological results.

Over the ensuing days, a repeated generalized rash with herpetic vesicles under continued high-dose acyclovir treatment (initial dose of $2700 \mathrm{mg} /$ day followed by $1500 \mathrm{mg} /$ day for approximately 30 days with respective adjustment to renal function) was noted (Fig. 3). In the light of a persevering course of HSV-2-induced multiple organ failure and continued high titers of "viral load" (that is $10^{5}$ to $10^{6}$ copies of HSV-2 per $\mathrm{ml}$ at days 14 and 21), geno-typization of the HSV-2 virus for acyclovir resistance was performed which revealed negative results. The patients' condition finally stabilized after 33 days of treatment. However, due to persisting lymphopenia and in view of the overall clinical severity, a prophylactic treatment with acyclovir (400 mg defined daily dose) was continued.

After approximately 1 month of intensive care treatment, an overall stabilization of his condition was noted. Norepinephrine was tapered and weaning from the ventilator was 


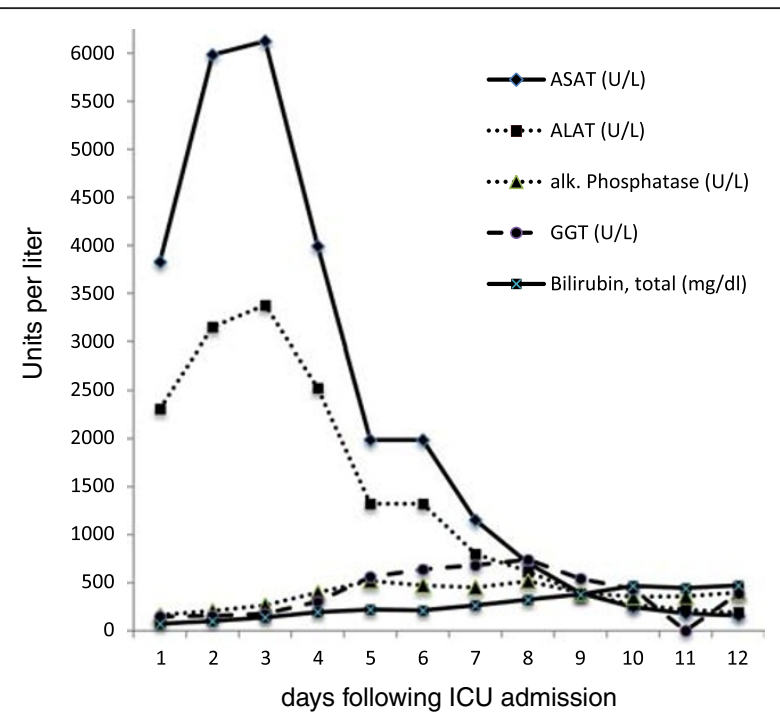

Fig. 2 Course of key laboratory parameters used to assess cellular damage and hepatic dysfunction in patient with multiple organ failure. Laboratory indices at respective days following intensive care unit admission. ALAT alanine aminotransferase, alk. alkaline, ASAT aspartate aminotransferase, GGT gamma-glutamyltransferase

advanced. A diagnosis of ICU-acquired weakness was established and rehabilitative measures were initiated.

\section{Discussion}

In the light of the available literature, HSV-2-induced multiple organ failure is a rare condition. HSV infection in adults is commonly associated with cutaneous facial (HSV-1) or urogenital infections (HSV-2) [4]. Of interest, approximately $60 \%$ of the Western population is HSV-1 colonized, whereas HSV-2 colonization occurs in approximately $12 \%$ of cases [4]. Oral HSV infection in adults may present as severe pharyngitis accounting for approximately $6 \%$ of cases in young adults. However, HSV-2

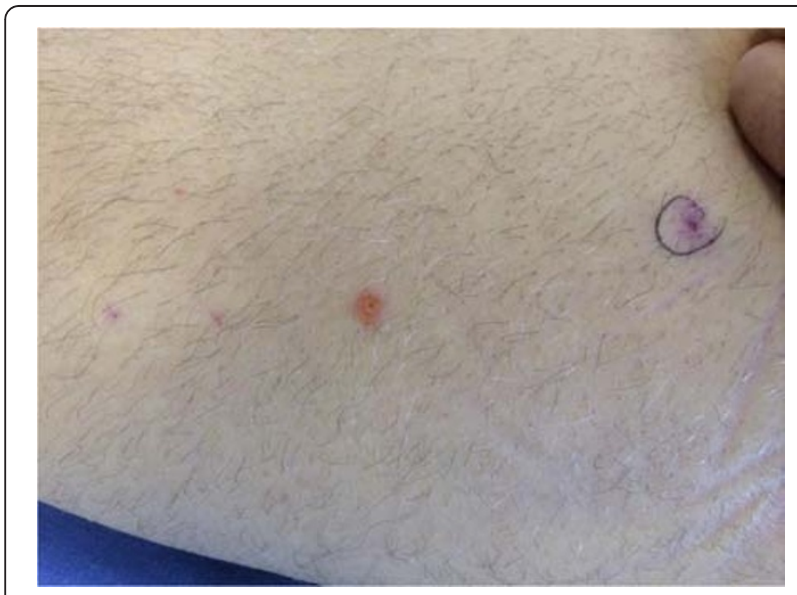

Fig. 3 Eruptions demonstrating generalized herpetic rash at day 8 following intensive care unit admission (left thigh) seems even scarcer and accounts for approximately $<0.5$ $\%$ of cases [5]. Systemic HSV infection with visceral viral dissemination may often present as ALF due to fulminant hepatic necrosis but represents less than $1 \%$ of cases of ALF [6]. Due to a lack of specific therapeutic options, HSV hepatitis is associated with mortality rates of up to $90 \%$ [7]. High-risk populations for a fatal course are immunosuppressed patients and pregnant patients (third trimester). Of interest, immunocompetency was deemed in approximately $24 \%$ of severely affected patients [7]. In our patient, testing for chronic viral disease including HIV testing, standard examinations including WBCs (following recovery from lymphopenia), immunoglobulins, distribution of immune cell subpopulations, and assessment of major histocompatibility complex (MHC) class II expression human leukocyte antigen- DR (HLA-DR) $[8,9]$ did not reveal a major immunocompromising condition. Nevertheless, in a case such as in our patient, a potential underlying immune deficiency should be ruled out.

Because of an unspecific clinical presentation, a diagnosis of HSV-induced hepatitis may frequently be missed and data demonstrate that the majority (that is $58 \%$ ) of patients are diagnosed post-mortem [7]. Improved survival rates are reported following early initiation of antiviral treatment. Retrospective analyses of patients with HSV hepatitis demonstrate significantly lower mortality rates following early acyclovir treatment when compared to controls (51\% versus $88 \%$ ). Treatment delay is associated with higher need for liver transplantation and higher mortality rates [7]. Thus, early initiation of antiviral therapy may be regarded mandatory to prevent fatal outcomes. Orthotopic liver transplantation (OLT) in the context of disseminated HSV infection should be evaluated carefully, as the risk for HSV recurrence seems increased and lifelong treatment with acyclovir may be needed following OLT [10]. Although there is a lack of conclusive data, intensivists should consider treating this life-threatening condition with antiviral medication over a sustained period of time until profound clinical improvement is observed. However, optimal dosage, especially in the presence of acute renal failure, and optimal timing of treatment for HSV-2-induced multiple organ failure remains elusive. In addition, it should be kept in mind that serum PCR levels (that is, respective assessment of viral load) may reveal positive results for a sustained period in time. This may be due to amplification of non-live viral particles and may be misleading in this clinical scenario.

\section{Conclusions}

In conclusion, this case demonstrates that HSV-2-induced multiple organ failure may develop in immunocompetent hosts following HSV-2 infectious tonsillitis. The clinical picture may masquerade as "routine" bacterial septic shock induced by bacterial tonsillitis and may lead to fatal clinical decisions if not recognized early and treated accordingly. 


\section{Consent}

Written informed consent was obtained from the patient for publication of this case report and accompanying images. A copy of the written consent is available for review by the Editor-in-Chief of this journal.

\section{Competing interests}

The authors declare that they have no competing interests.

\section{Authors' contributions}

UG and JCS collected all data, treated the patient, and drafted the manuscript. CB and SB performed laboratory investigations/histopathological examinations and provided expert consultation. JFD provided expert hepatological consultation. JCS coordinated the input of all authors. All authors read and approved the final version of the manuscript.

\section{Acknowledgements}

The authors thank the patient for kindly providing informed consent to the publication of the data. Furthermore, the authors thank all ICU nurses and laboratory personnel for their dedicated care and efforts. The authors thank PD Dr P. Sendi, Dept. of Infectious Diseases, Inselspital, Bern, for expert advice/consultations. The authors also thank PD Dr med. S. Zimmerli, Dept of Infectious Diseases, Inselspital, Bern, for expert advice/consultations and provision of photographs.

\section{Author details}

${ }^{1}$ Department of Intensive Care Medicine, Inselspital, Bern University Hospital, CH 3010 Bern, Switzerland. ²Department of Infectious Diseases, Inselspital, Bern University Hospital, CH 3010 Bern, Switzerland. ${ }^{3}$ Institute of Pathology, University of Bern, CH 3010 Bern, Switzerland. ${ }^{4}$ Department of Visceral Surgery and Medicine, Inselspital, Bern University Hospital, CH 3010 Bern, Switzerland

\section{Received: 16 March 2015 Accepted: 30 November 2015}

\section{H.}

\section{References}

1. [Sore throat and chronic tonsillitis (an analytical review)]. Vestnik otorinolaringologii 2012(1):68-76.

2. Bathala $S$, Eccles R. A review on the mechanism of sore throat in tonsillitis. J Laryngol Otol. 2013;127(3):227-32.

3. Bird JH, Biggs TC, King EV. Controversies in the management of acute tonsillitis: an evidence-based review. Clin Otolaryngol. 2014;39(6):368-74

4. Rosenthal SL, Stanberry LR, Biro FM, Slaoui M, Francotte M, Koutsoukos M, et al. Seroprevalence of herpes simplex virus types 1 and 2 and cytomegalovirus in adolescents. Clin Infect Dis. 1997;24(2):135-9.

5. McMillan JA, Weiner LB, Higgins AM, Lamparella VJ. Pharyngitis associated with herpes simplex virus in college students. Pediatr Infect Dis J. 1993;12(4):280-4.

6. Schiodt FV, Davern TJ, Shakil AO, McGuire B, Samuel G, Lee WM. Viral hepatitis-related acute liver failure. Am J Gastroenterol. 2003;98(2):448-53.

7. Norvell JP, Blei AT, Jovanovic BD, Levitsky J. Herpes simplex virus hepatitis: an analysis of the published literature and institutional cases. Liver Transpl. 2007;13(10):1428-34

8. Schefold JC. Measurement of monocytic HLA-DR (mHLA-DR) expression in patients with severe sepsis and septic shock: assessment of immune organ failure. Intensive Care Med. 2010;36(11):1810-2.

9. Schefold JC, Hasper D, Reinke P, Monneret G, Volk HD. Consider delayed immunosuppression into the concept of sepsis. Crit Care Med. 2008;36(11):3118.

10. Riediger C, Sauer P, Matevossian E, Muller MW, Buchler P, Friess H. Herpes simplex virus sepsis and acute liver failure. Clin Transplant. 2009;23 Suppl 21:37-41.

\section{Submit your next manuscript to BioMed Central and we will help you at every step:}

- We accept pre-submission inquiries

- Our selector tool helps you to find the most relevant journal

- We provide round the clock customer support

- Convenient online submission

- Thorough peer review

- Inclusion in PubMed and all major indexing services

- Maximum visibility for your research

Submit your manuscript at www.biomedcentral.com/submit 